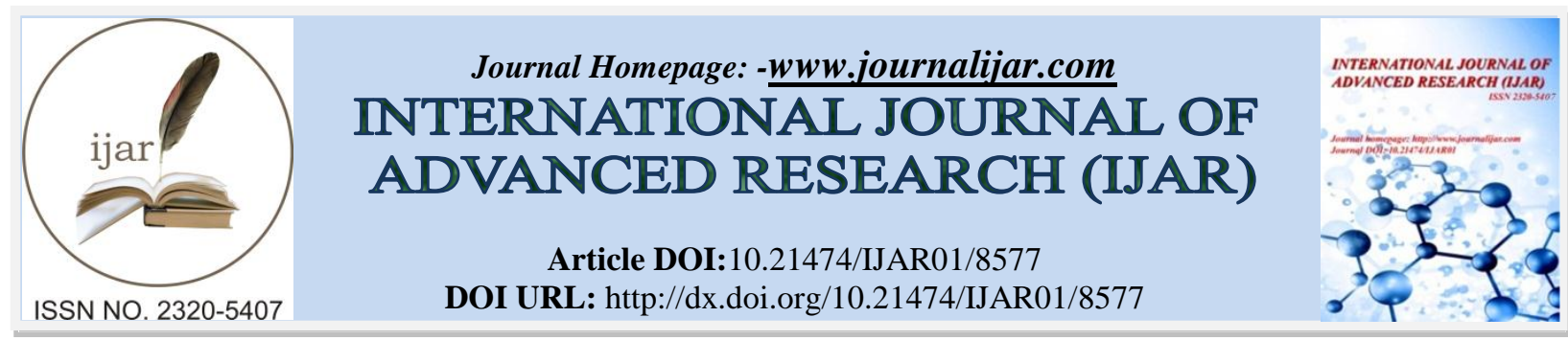

RESEARCH ARTICLE

\title{
TYPE-2 FUZZY SUPERVISOR FOR A STAND-ALONE SYSTEM USING PMSG VARIABLE SPEED WIND TURBINE.
}

\author{
AlnufaielafiS. \\ Department Of Electrical Engineering, College Of Engineering Shaqra University Dawadmi, Kingdom Of Saudi \\ Arabia.
}

\section{Manuscript Info}

\section{Manuscript History}

Received: 14 December 2018

Final Accepted: 16 January 2019

Published: February 2019

\section{Key words:-}

wind turbine; fuzzy logic, wind energy conversion, system.boost converter,

Voltage source PWM inverter.

\section{Abstract}

In this paper treats the smart management for a stand-alone system using a wind energy conversion system (WECS) based on variable speed synchronous generator and battery system for storing the extra wind energy. The smart management is ensured by a type-fuzzy supervisor, which allows obtain an optimal behavior of the system and to ensure the load requirement. Simulation results are presented to show that the performances of proposed method et its capacity to guarantee a good energy efficiency and to involves battery life extending.

Copy Right, IJAR, 2019,. All rights reserved.

\section{Introduction:-}

Economic growth since the industrial revolution has been possible thanks to abundant sources of affordable energy, in the form of coal, oil and gas. However, to mitigate climate change, we must urgently move away from fossil fuels, and a rapid transition to a sustainable energy system is necessary [1], [2].

Wind energy, is one of the available non-conventional energy sources, which is clean and an infinite natural resource. Variable speed wind energy systems have several advantages compared with fixed speed wind energy systems such as yielding maximum power output, developing low amount of mechanical stress, improving efficiency and power quality[3]. Power electronics devices with a variable speed system are very important, where AC-DC converter is used to convert AC voltage with variable amplitude and frequency at the generator side to DC voltage at the DC-link voltage. The $\mathrm{DC}$ voltage is converted again to $\mathrm{AC}$ voltage with constant amplitude and frequency at theload side for electrical utilization. The reliability of the variable speed wind energy systems can be improved significantly by using a permanent magnet synchronous generator (PMSG). PMSG has several advantages over other types of generators which are used in wind energy systems such as its simple structure, ability of operation at slow speed, self-excitation capability leading to high power factor and high efficiency operation. With low speed of PMSG operation there is no need for a gearbox which often suffers from faults and requires regular maintenance making the system unreliable. A principal drawback of these technologies is the intermittent nature of the supply. The wind energy relies upon favourable weather conditions to generate maximum power. Even if, the wind energy can be predicted based on a prior wind study, the power generation is stochastic. Thus, there is no guarantee that a residential load will be supplied at any given time by a renewable energy source. For this, in the case of stand-alone wind energy systems we use batteries as storage device to handle the power variations[4]-[6].

Corresponding Author:-Alnufaielafi S.

Address:-Department Of Electrical Engineering, College Of Engineering Shaqra University Dawadmi, Kingdom Of Saudi Arabia. 
To manage the energy flow efficiently and respond effectively to the energy demand of the consumer, it is very important to design supervisor able to incorporateinitsstructure human expertise, like fuzzy logic. So, several works exploiting fuzzy logic have been presented in the literature[7]. However, in the case we have poor knowledge, the classical fuzzy systems, called type-1 fuzzy logic systems, have difficulties in modelling and minimizing the effect of uncertainties such as linguistic uncertainties and noisy training data. In the last decades, a notable attention has been paid to another type of fuzzy system called Type-2 fuzzy logic system (T2FLS). In T2FLS, the uncertainty is represented using a function, which is itself a Type-1 fuzzy number and that is why T2FLS is referred to as fuzzy system. The membership functions of T2 fuzzy sets are three dimensional and include a footprint of uncertainty (FOU) with a new third dimension of Type-2 fuzzy sets. A FOU provides additional degrees of freedom that make it possible to directly model and handle uncertainties and consequently, T2FLS has the potential to outperform T1FLS in such cases.

In this paper, we propose a T2FLS supervisor for a wind energy system based on a PMSG and batteries. WECS including a variable speed synchronous generator and a battery bank. The objective is to manage power production and power storage according to wind condition and load demand. Indeed, the load power is provided mainly by wind power, and when this power is not enough, we can use batteries to supply the missing part. When the production exceeds the demand, the batteries are charged if they are not full, otherwise a ballast resistor is used to dissipate the excess of production.

\section{System Description:-}

Consider a stand-alone system with a $5.5 \mathrm{~kW}$ pump, a $7.5 \mathrm{~kW}$ induction motor and a $10 \mathrm{~kW}$ water heater, powered by a $30 \mathrm{kVA}$ synchronous generator wind turbine and a battery storage (figure. 1).

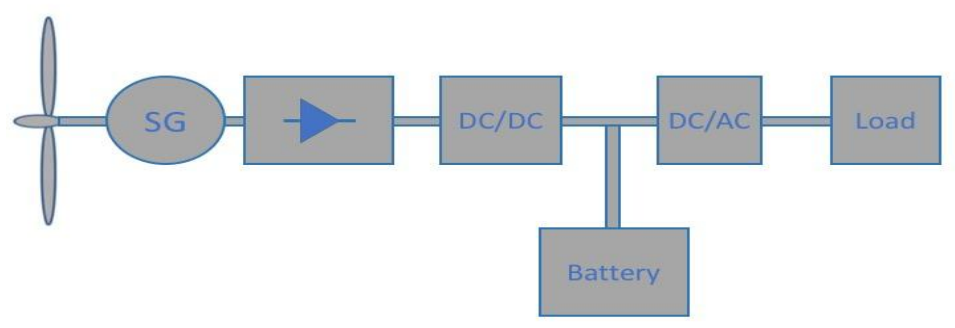

Fig. 1:-WECS for a stand-alone system.

In this variable speed wind turbine, a diode rectifier will rectify the $\mathrm{AC}$ power, then a boost converter will increase the DC voltage obtained to be suitable for both battery charging process and PWM inverter's operation.

If wind conditions are favourable, the wind turbine will be the main provider for the load. If the available wind does not produce the required quantities of power and the battery's capacity is enough, the battery will be switch on to give power to load. If wind power exceeds the load demand, the surplus can be stored in the battery and if the battery is full, the surplus will be discharged into a ballast resistance. Thus, the battery is not the main provider to load, so the charge-discharge cycle is reduced, battery's lifetime is extended[8], [9].

We proposed a fuzzy controller to achieve these purposes. To do this, our controller needs two information's: the state of charge $(\mathrm{SC})$ of the battery and the error between the wind power and the load demand $(\Delta \mathrm{P})$. Then the controller will decide duty cycle of the boost converter (D) for charging the battery, the moment to switch on and off the battery (S1) and the moment to discharge the surplus into dumb resistance (S2) (figure. 2). 


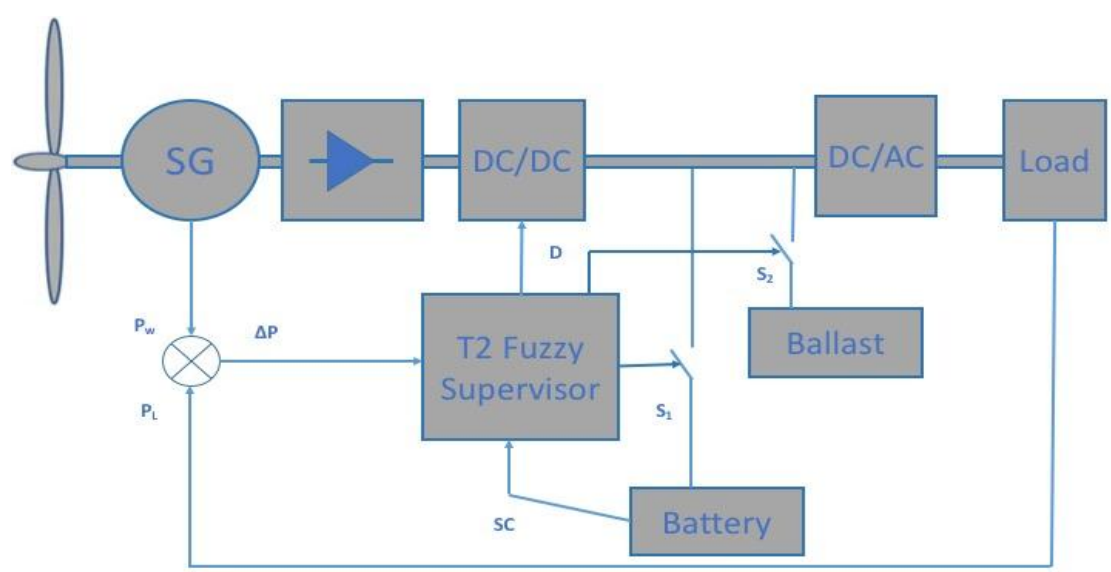

Fig. 2:-Proposed Scheme

\section{Model of wind turbine:-}

The static characteristic of wind turbine can be described by the relation between total power in the wind and mechanical power of wind turbine as in (1). It presents a basic model for wind turbine in electric power system.

$P_{w}=\frac{1}{2} \rho \pi R_{\text {turbine }}^{2} v_{\text {wind }}^{3}$

In wind power equation (1), $\rho$ is air density $(1.225 \mathrm{~kg} / \mathrm{m} 3), \mathrm{R}$ turbine is the turbine radius in meters, $v_{\text {wind is the }}$ wind speed in $\mathrm{m} / \mathrm{s}$. It is not possible to extract all kinetic energy of wind, thus it is extracted a fraction of power in wind as given in (2) and it is called power coefficient $\mathrm{Cp}$ of the wind turbine.

$P_{m}=\frac{1}{2} C_{p} \rho \pi R_{\text {turbine }}^{2} v_{\text {wind }}^{3}$

$P_{m}$

is the mechanical power of wind turbine. The maximum power coefficient is given as $\mathrm{Cp}=0.59$. This coefficient is also known as Betz's limit. It can be expressed as a function of tip speed ratio- $\lambda$ and pitch angle- $\theta$.

The tip speed ratio $\lambda$ is defined as (3):

$\lambda=\frac{\omega_{\text {turbine }} R}{v_{\text {wind }}}$

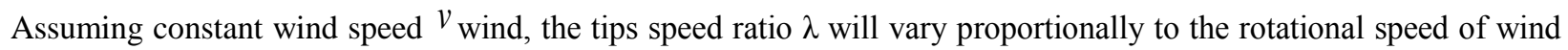
turbine rotor[10]-[12]. The highest value of $\mathrm{Cp}$ is typically obtained for $\lambda$ values in the range of 8 to 9 (when the tip of the blades moves 8 to 9 times faster than incoming wind). On modern wind turbines, it is possible to adjust the pitch angle of the entire blade through servo mechanism[13], [14]. If $\mathrm{Cp}-\lambda$ curve is known for specific wind turbine with a turbine rotor radius Rturbine, it is easy to construct the curve of $\mathrm{Cp}$ against rotational speed for any wind speed.

In this paper, we use a simple wind turbine's model available in Matlab Simulink, where inputs are wind speed and rotor speed, output is the mechanical power.

\section{Power Electronic Device:-}

1. Diode rectifier

Output voltage of the three phase diode bridge rectifier:

$V_{r e c}=V_{R M S} \sqrt{2} \frac{\sin (\pi / 6)}{\pi / 6}=1.35 V_{R M S}$

Where VRMS is root-mean-square value of input voltage. 


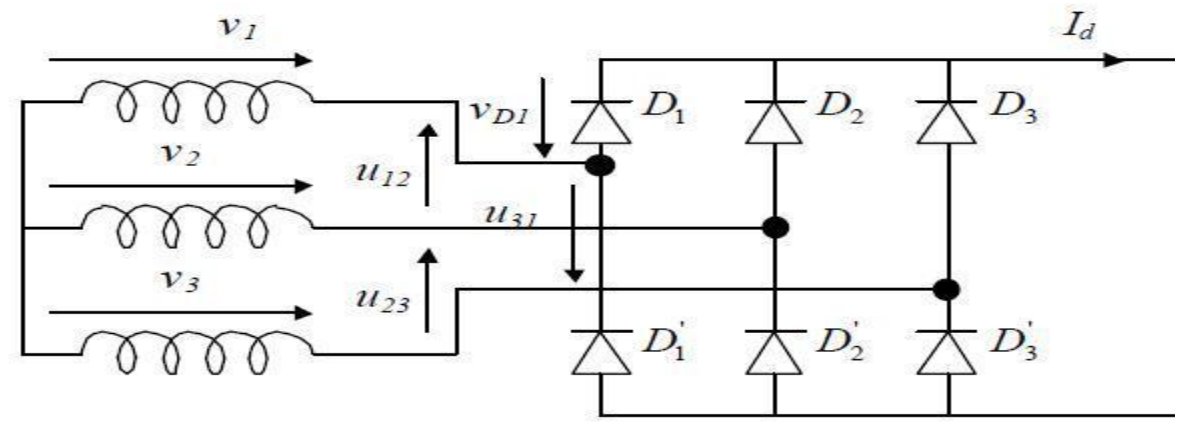

Fig. 3:-Three phase bridge rectifier.

\section{DC-DC boost converter:-}

Output voltage of the boost converter[14]:

$V_{D C}=V_{\text {rec }} \cdot \frac{1}{1-D}$

Where the switching frequency fs of switch $\mathrm{S}$ equal to the inverse of the switching period Ts generally lies in the range of $1 \mathrm{kHz}$ to $1 \mathrm{MHz}$, depending on the switching speed of the semiconductor devices. The duty ratio $\mathrm{D}$ is the fraction of time that the switch spends in position 1, and is a number between zero and one. Our fuzzy controller will decide the duty cycle D for this boost converter to have an output voltage suitable for the PWM inverter's functioning and battery's charging process.

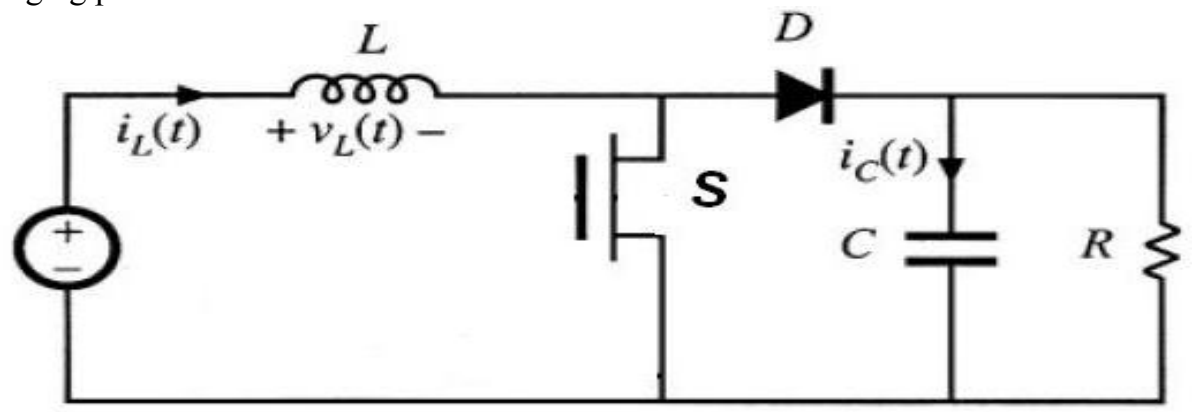

Fig. 4:-Boost converter.

Value of inductor $\mathrm{L}$ is chosen to minimize the ripple in current $\Delta \mathrm{i}$ :

$$
L=\frac{V_{r e c}}{2 \Delta i} D T{ }_{s}
$$

Select the capacitor value $\mathrm{C}$ to obtain a given output voltage ripple peak magnitude $\Delta \mathrm{v}$ :

$C=\frac{V_{D C}}{2 R \Delta v} D T$

Here we choose $\mathrm{L}=4 \mathrm{mH}, \mathrm{C}=5000 \mu \mathrm{F}$ to have an acceptable ripple in voltage and current.

\section{Voltage source PWM inverter:-}

Value of inductor $\mathrm{L}$ is chosen to minimize the ripple in current $\Delta \mathrm{i}$ :

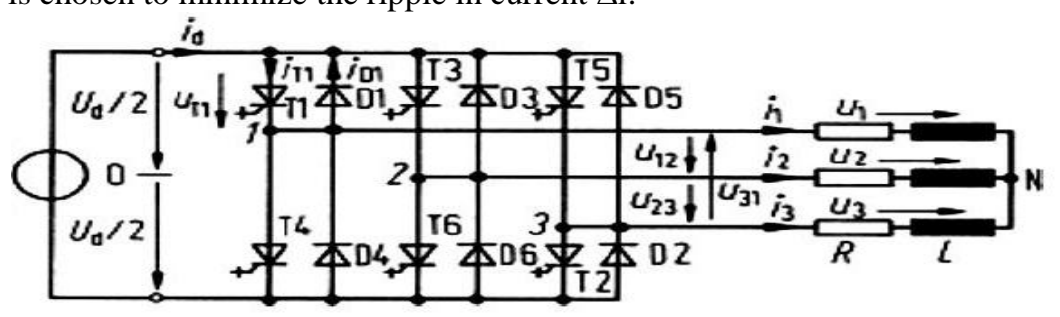


Fig. 5:-Voltage source PWM inverter.

The modulation ratio is defined using reference and triangular voltage amplitudes :

$$
m=\frac{u_{r e f}}{u_{t r i}}
$$

In the region $m \leq 1$ the fundamental output line-to-line voltage is a linear function of $\mathrm{m}$ :

$$
U_{a b}=\frac{\sqrt{3}}{2 \sqrt{2}} m \cdot U_{D C}
$$

Here we use the low-pass filter:

$$
f_{c}=\frac{1}{2 \pi \sqrt{L C}}
$$

Here we choose $\mathrm{L}=8 \mathrm{mH}, \mathrm{C}=100 \mu \mathrm{F}$ to pass the 1 st and 3rd harmonic of the output voltage (fc=177 Hz), assure the smooth sinusoidal output voltage for the load.

\section{Fuzzy Supervisor:-}

Recently, the applications of type-2 fuzzy logic (T2FL) to uncertain control processes have received considerable attention .This concept was also introduced by LoftiZadeh in 1975. [15]. Nevertheless, the first T2FL system was developed and presented only 23 years later by N. Karnik and J. Mendel[16]. As J. Mendel defines, type-2 is an expanded and richer fuzzy logic which enables to better handle the uncertainty[17],[16].This technique is a relatively new. Indeed, in last years it has begun to interest researchers around the world, the number of publications increases at a high rate. Most of the authors working in this research consider that T2FL can outperform their counterparts T1FL because they can model complex processes, it's characterized by MFs that are themselves fuzzy and it is usually more robust and better able to eliminate oscillations. The Interval Type-2 (IT2) [15], [16], [18]a special case of type-2 FLS, are currently the most widely used for their reduced computational cost.

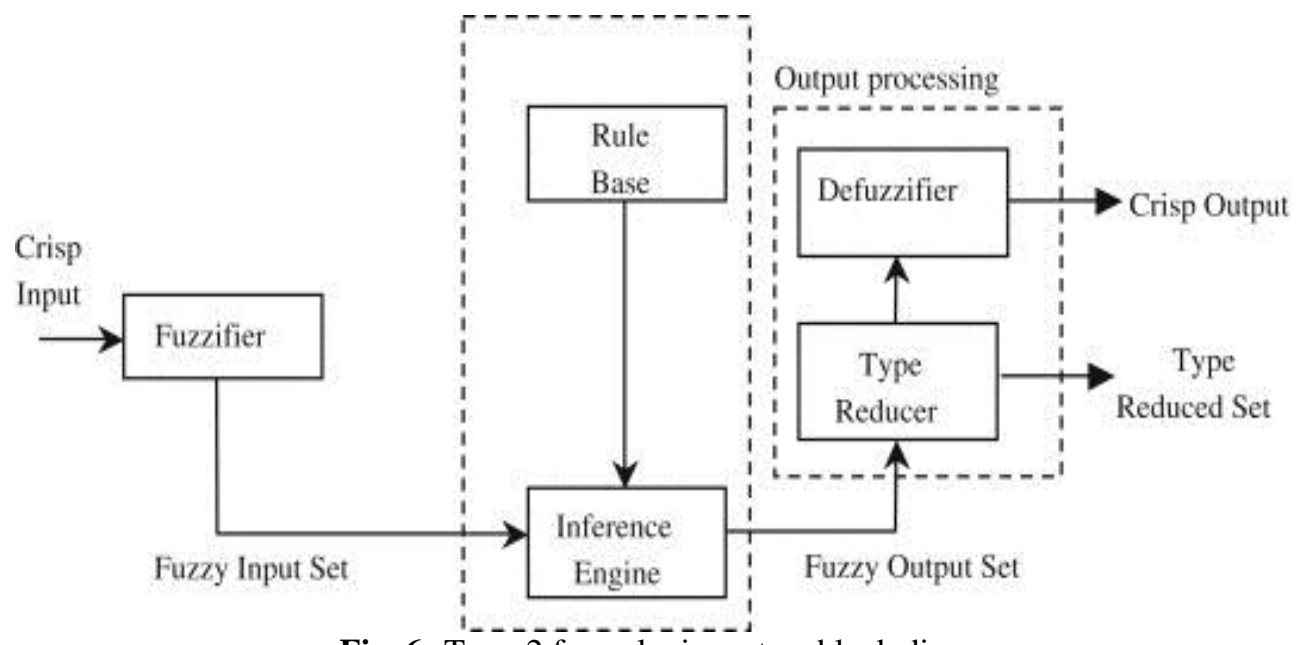

Fig. 6:-Type-2 fuzzy logic system block diagram.

The proposed T2FLS supervisor (figure 5) uses as inputs : the battery's state of charge (SC) and the power error $\Delta \mathrm{P}$ (difference between wind turbine power and load demand). As outputs, we have the duty cycle D applied to the boost converter in order to charge the battery (ensuring a safe and efficiency functioning) and to guarantee the voltage's input sufficient for the voltage-source PWM inverter. For this, we define the following linguistic term sets:

Error of power $\Delta \mathrm{P}$ [N(Negative); SP(Small Positive); $\mathrm{P}($ Positive); BP(Big Positive)] (figure 6). Battery state-ofcharge SC [Empty, Average, Full], varying from $0 \%$ to $100 \%$, if SC is smaller than $20 \%$ means the battery is empty (figure 7). Duty cycle D [Small, Average, Big, VeryBig], varying from $22 \%$ to $34 \%$ because of the input voltage's limit of the PWM inverter and the charging voltage for the battery (figure 8). Switch S1 and S2 [Open, Close](figure 9). 


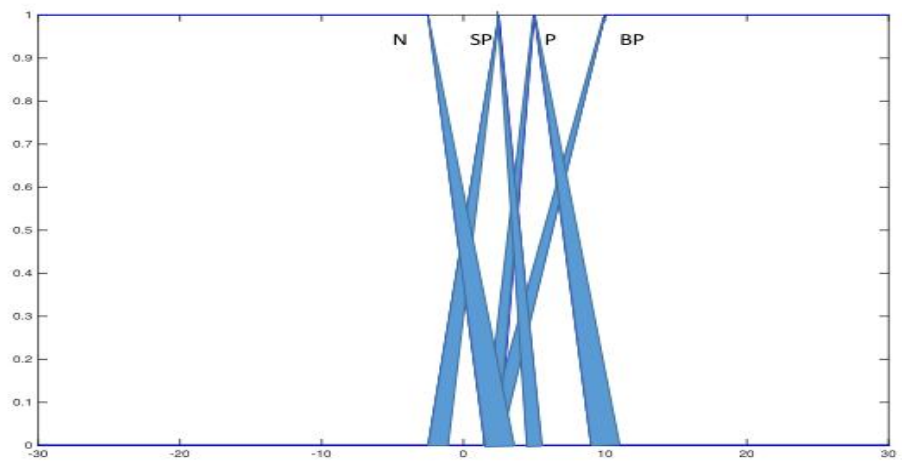

Fig. 7:-Five terms of error power $\Delta \mathrm{P}$.

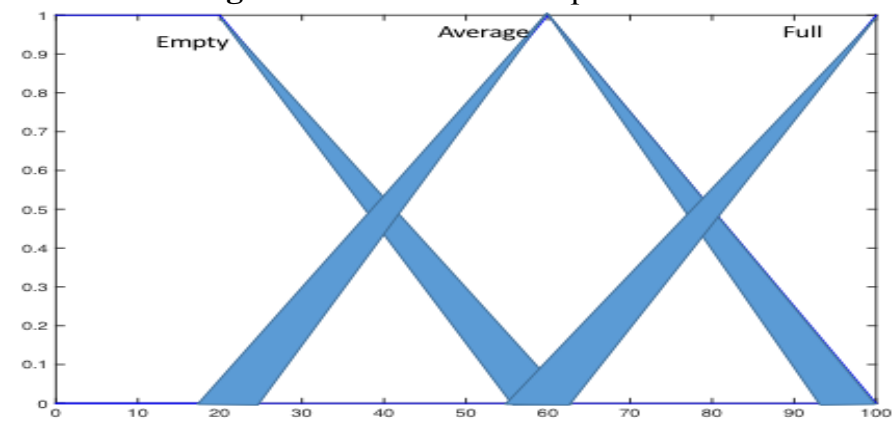

Fig. 8:-Three terms of battery state-of-charge SC.

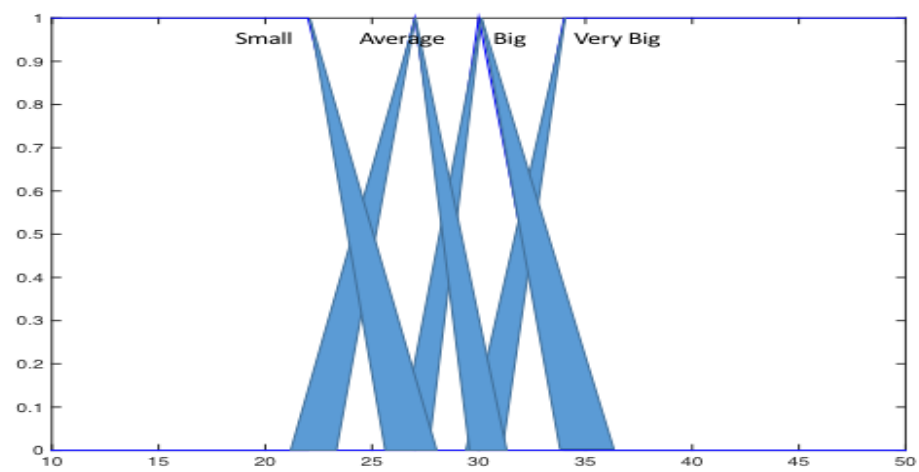

Fig. 9:-Five terms of duty cycle D.

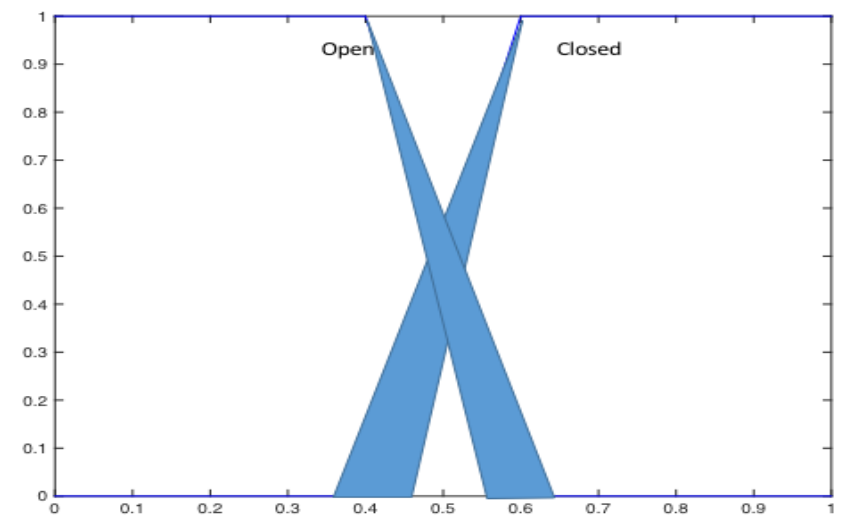

Fig. 10:-Two terms of state of switch S1 and S2. 
Tables 1, 2, 3:-summarize the used fuzzy rules.

Tabel 1:-Rules of D.

\begin{tabular}{|c|c|c|c|c|}
\hline \multicolumn{2}{|c|}{ S2 } & \multicolumn{3}{c|}{ SC } \\
\cline { 3 - 5 } & Full & Average & Empty \\
\hline \multirow{3}{*}{$\Delta \mathrm{P}$} & $\mathrm{N}$ & Open & Open & Open \\
\cline { 2 - 5 } & $\mathrm{SP}$ & Open & Open & Open \\
\cline { 2 - 5 } & $\mathrm{P}$ & Open & Open & Open \\
\cline { 2 - 5 } & $\mathrm{VP}$ & Close & Open & \\
\hline
\end{tabular}

Tabel2:-Rules of S1

\begin{tabular}{|c|c|c|c|c|}
\hline \multicolumn{2}{|c|}{ S1 } & \multicolumn{3}{c|}{ SC } \\
\cline { 3 - 5 } & N & Full & Average & Empty \\
\hline \multirow{3}{*}{$\Delta \mathrm{P}$} & SP & close & close & Open \\
\cline { 2 - 5 } & P & Open & Open & Open \\
\cline { 2 - 5 } & VP & Open & Open & Open \\
\cline { 2 - 5 } & & & Open & Open \\
\hline
\end{tabular}

Tabel3:-Rules of S2

\begin{tabular}{|c|c|c|c|c|}
\hline \multirow{2}{*}{\multicolumn{2}{|c|}{ S2 }} & \multicolumn{3}{|c|}{$\mathrm{SC}$} \\
\hline & & Full & Average & Empty \\
\hline \multirow{4}{*}{$\Delta \mathrm{P}$} & $\mathrm{N}$ & Open & Open & Open \\
\hline & SP & Open & Open & Open \\
\hline & $\mathrm{P}$ & Open & Open & Open \\
\hline & VP & Close & Open & Open \\
\hline
\end{tabular}

\section{Results:-}

\section{Simulation:-}

In order to verify the effectiveness of the proposed approach, some simulation studies were carried out using MATLAB/SIMULINK. We consider several power variations to show the efficiency of the proposed approach. We assume that the initial value of the state of charge (SC) is $90 \%$ and the load demand is given by (figure 10).

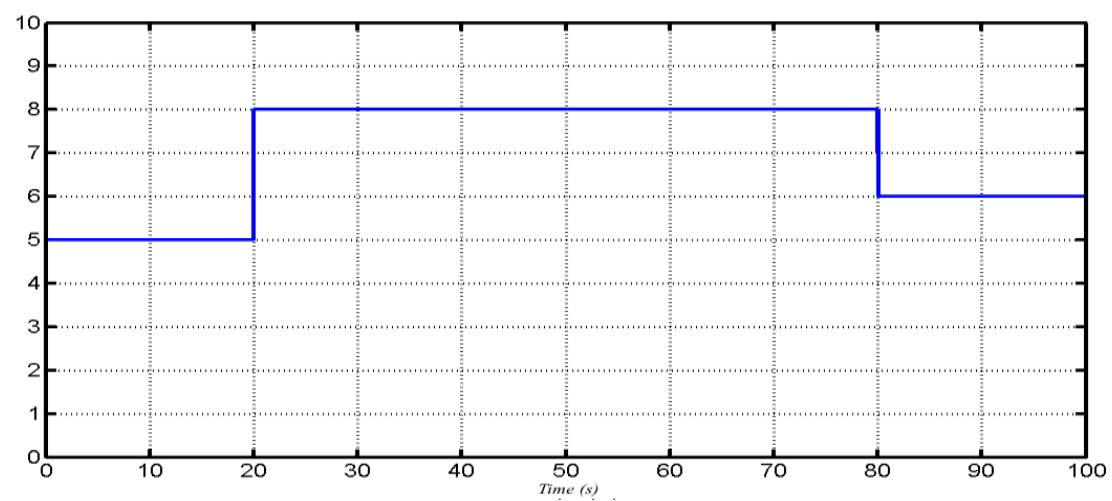

Fig. 11:-Load demand (Kw)

(Figure 11) gives the power flux in the system. We remark that all time the powerr demand is satisfied. Indeed, when we have the produced power is less then demand ( $\triangle \mathrm{P}<0$, figure 12), we use battery to reach the desired value. In the case where we produce enough and battery is not full, we can chargingitaccording to the established constraint (SC $<95 \%$ ). (Figure 13) gives the load voltage. 


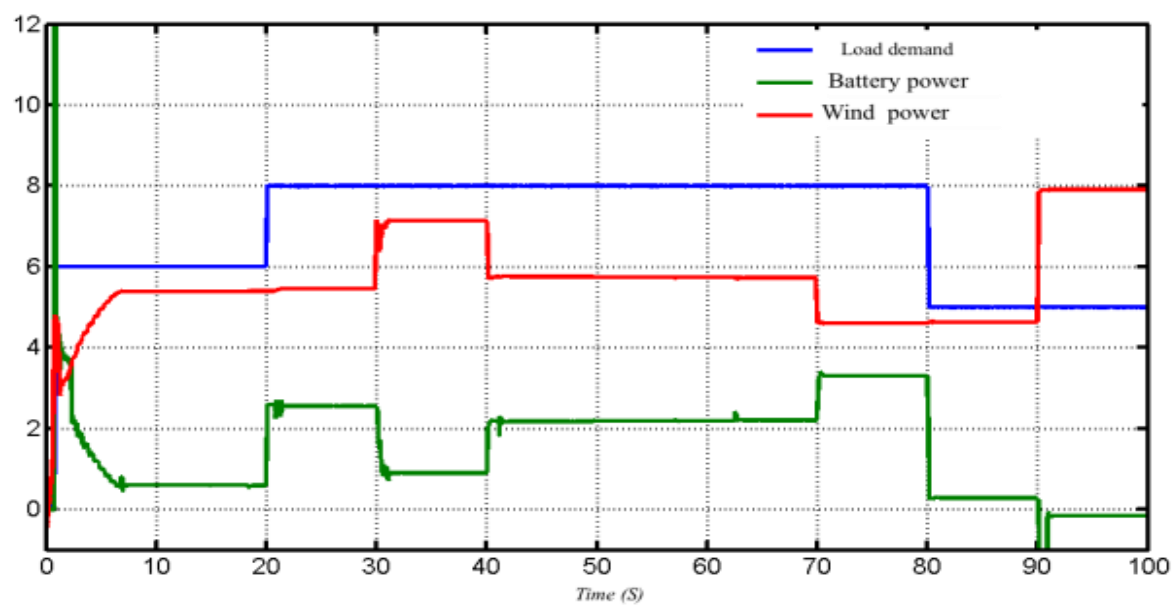

Fig. 12:-Load demand, battery power, wind power $(\mathrm{Kw})$.

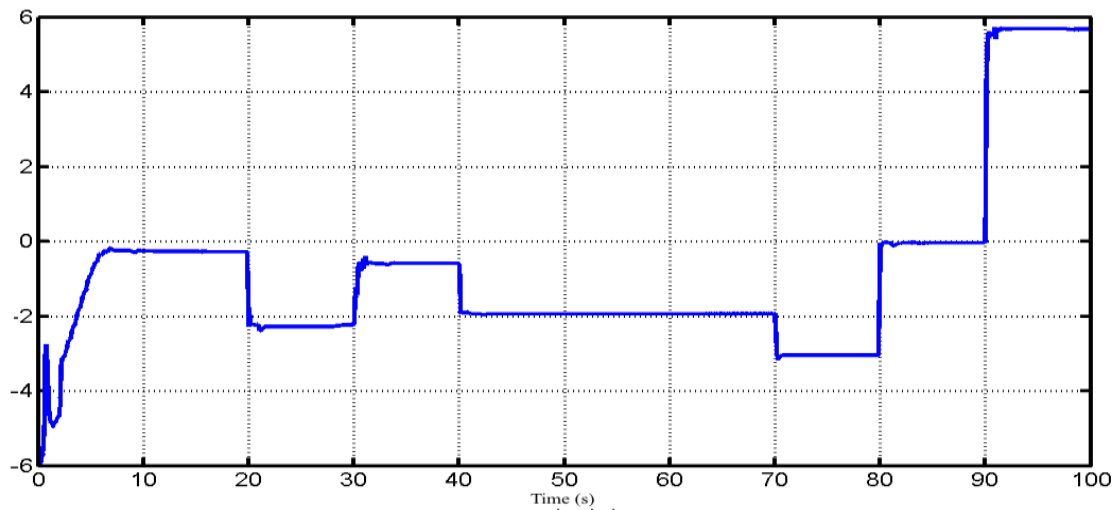

Fig. 13:- $\Delta \mathrm{P}(\mathrm{Kw})$.

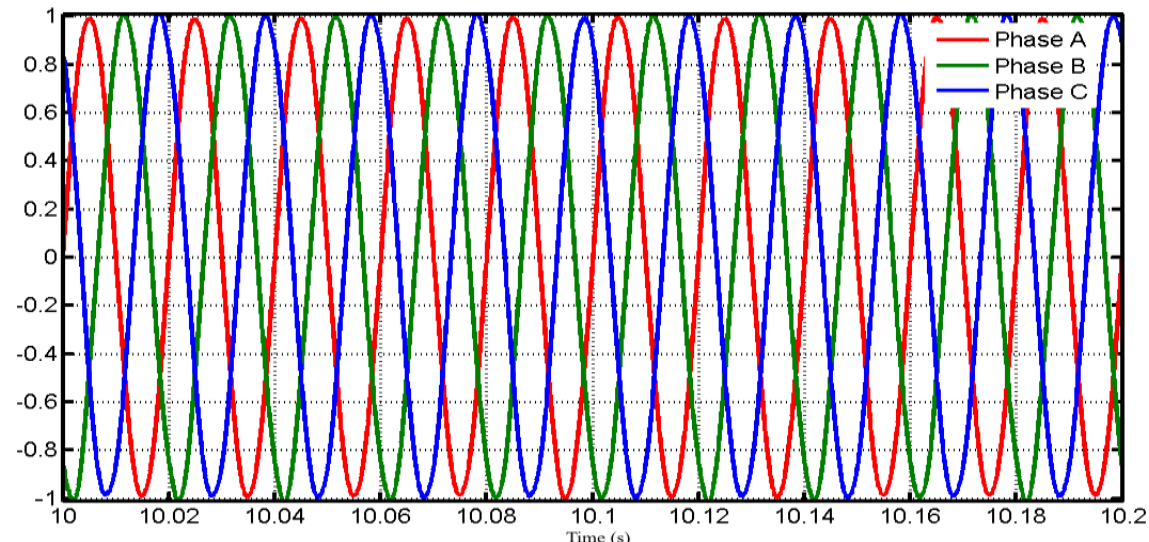

Fig. 14:-Load voltage (PU).

These results show that our controller worked well. It assured the load demand despite wind condition with a good power quality and regulated battery charging process to prevent the battery from gassing and sulphating.

\section{Conclusions:-}

In this work, Type-2 fuzzy supervisor is presented to ensure a smart management for electricity distribution for standalone system. With information about load and battery state-of-charge, control signals were generated to manage well the power production for any wind conditions in respecting load demand. The simulation results show a good behaviour of our controller. Future works will concern, hybrid power systems combining several sources. 


\section{References:-}

1. Sinha, 'A Power System Reliability Evaluation Technique and Education Tool for Wind Energy Integration'. Arizona State University, 2012.

2. S. Singh, D. Zindani, A. K. Roy, and K. Kumar, 'Application of Renewable Energy System With Fuzzy Logic', in Advanced Fuzzy Logic Approaches in Engineering Science, IGI Global, 2019, pp. 284-309.

3. G. E. Saady, E. A. Ibrahim, H. Ziedan, and M. M. Soliman, 'Analysis of wind turbine driven permanent magnet synchronous generator under different loading conditions', Innov. Syst. Des. Eng., vol. 4, no. 14, 2013.

4. S. Ramsumar, 'The control of power electronic converters for grid code compliance in wind energy generation systems'. 2015.

5. S. H. Qazi and M. W. Mustafa, 'Mitigation of Load Harmonics from Grid Connected Wind Turbine: Using Shunt Active Power Filter'. UniversitiTeknologi Malaysia, 2016.

6. S. Bubshait, 'Wind Farm Advanced Modeling and Control for Smart-Grid Support'. Colorado School of Mines, 2018.

7. M. N. I. Sarkar, L. G. Meegahapola, and M. Datta, 'Reactive Power Management in Renewable Rich Power Grids: A Review of Grid-Codes, Renewable Generators, Support Devices, Control Strategies and Optimization Algorithms', IEEE Access, 2018.

8. S. Faquir, A. Yahyaouy, H. Tairi, and J. Sabor, 'Energy management in a hybrid PV/wind/battery system using a type-1 fuzzy logic computer algorithm', Int. J. Intell. Eng. Informatics, vol. 4, no. 3-4, pp. 229-244, 2016.

9. Vural, O. Erdinc, and M. Uzunoglu, 'Parallel combination of FC and UC for vehicular power systems using a multi-input converter-based power interface', Energy Convers. Manag., vol. 51, no. 12, pp. 2613-2622, 2010.

10. F. Gurin, D. Lefebvre, A. B. Mboup, J.-Y. Pard, E. Lemains, and P. A. S. Ndiaye, 'Hybrid modeling for performance evaluation of multisource renewable energy systems', IEEE Trans. Autom. Sci. Eng., vol. 8, no. 3, pp. 570-580, 2011.

11. S. Zerkaoui, 'Online Hierarchical Controller for Hybrid Power System', ISRN Renew. Energy, vol. 2012, 2012.

12. L. Ciabattoni, M. Grisostomi, G. Ippoliti, and S. Longhi, 'Household Electrical Consumption Modeling through Fuzzy Logic Approach'.

13. W. E. Addisu, 'Intelligent load frequency control in an isolated wind-solar PV-micro turbine-diesel based micro-grid using V2G integration'. UiTNorgesarktiskeuniversitet, 2017.

14. P. Dey, 'A coordinated control of PMSG based wind turbine generator to improve fault-ride-through performance and transient stability', 2018.

15. O. D. Mipoung, 'Enhancement of Frequency Support Capabilities of Type 1 and Type 2 Wind Turbines'. Concordia University, 2012.

16. N. N. Karnik and J. M. Mendel, 'Introduction to type-2 fuzzy logic systems', in Fuzzy Systems Proceedings, 1998. IEEE World Congress on Computational Intelligence., The 1998 IEEE International Conference on, 1998, vol. 2, pp. 915-920.

17. N. N. Karnik and J. M. Mendel, 'Type-2 fuzzy logic systems: type-reduction', in Systems, Man, and Cybernetics, 1998. 1998 IEEE International Conference on, 1998, vol. 2, pp. 2046-2051.

18. N. Hamouda et al., 'Type-2 Fuzzy Logic Predictive Control of a Grid Connected Wind Power Systems with Integrated Active Power Filter Capabilities', J. Power Electron., vol. 17, no. 6, pp. 1587-1599, 2017. 